\title{
O PERFIL DE CONHECIMENTO SOBRE SERES VIVOS PELOS ESTUDANTES DA COOPEC: UMA FERRAMENTA PARA PLANEJAR UM ENSINO DE CIÊNCIAS
}

\author{
Darcy Ribeiro de Castro* \\ Nelson Rui Ribas Bejarano**
}

RESUMO: Este trabalho objetivou fazer um levantamento dos conhecimentos prévios dos alunos das séries iniciais da Cooperativa de Ensino de CentralCOOPEC, cidade de Central, Bahia-BA, em fevereiro de 2009, bem como descrever o contexto de ensino na sala de aula das referidas turmas durante aquele ano letivo. Este estudo faz parte de uma dissertação de mestrado e envolveu conteúdos de alguns aspectos de seres vivos (identificação, tamanho e função) nas séries iniciais ( $2^{\circ}$ ao $5^{\circ}$ ano), e crianças com faixa etária entre 7 e 11 anos de idade. Para desenvolvê-lo, usamos o referencial vygotskyano acerca dos conhecimentos espontâneos e científicos das crianças e outro biológico, sobre as concepções espontâneas delas nessa área. Aplicamos questionários com questões generalistas nas turmas para fins de obter informações sobre o conhecimento espontâneo dos estudantes com respeito aos seres vivos; discutimos com as professoras os conhecimentos trazidos à escola pelos estudantes nas reuniões bimestrais e aplicamos um questionário para que elas respondessem ao final do último encontro. A análise de dados, a partir das respostas de alunos e das professoras, foi realizada em todas as séries com base no método comparativo, com o intuito de evidenciar o que conhecem as crianças sobre os referidos aspectos de seres vivos, como ponto de partida para planejamento de ensino sobre o tema.

Palavras-chave: Séries Iniciais do Ensino Fundamental; Conhecimentos Prévios; Seres Vivos; Referencial Vigotskyano; Planejamento de Ensino.

PROFILE OF KNOWLEDGE OF LIVING BEINGS BY COOPEC STUDENTS: A TOOL FOR PLANNING SCIENCE TEACHING

ABSTRACT: This study aimed to survey the prior knowledge of students from COOPEC-Central - Central, Bahia - at initial grades of Elementary School, in February 2009, describing the context of teaching in classrooms during that school year. This study is part of a masters dissertation and involved content of some aspects of living beings (identification, size and function) in the early grades (2nd to 5 th year), children aged between 7 and 11 . We developed our studies based on Vygotsky's children's spontaneous and scientific knowledge theory and on other spontaneous conceptions reference in that area. We applied questionnaires with general questions to students in order to obtain information on students' spontaneous knowledge with respect to living beings; we discussed with teachers the knowledge brought by the students to school in bimonthly meetings; and we applied a questionnaire to which teachers responded at end of the last meeting. Data analysis - with the students' and teachers' reponses - was performed considering all the initial Elementary School grades, based on the comparative method in order to highlight what children actually knew about living beings, as a starting point for planning education on the subject.

Keywords: Initial series, prior knowledge, living beings, Vygotsky, education planning.
*MestreemEnsino,Filosofia eHistória das Ciências pela Universidade Federal da Bahia (UFBA). Professor da Universidade do Estado da Bahia (UNEB). Email: dcastro@uneb.br

* *Doutor em educação pela Universidade de São Paulo (USP). Professor do Instituto de Química da Universidade Federal da Bahia (IOUFBA) e do Programa de Pós-Graduação em Ensino, Filosofia e História das Ciências da Universidade Federal da Bahia (UFBA) e da Universidade Estadual de Feira de Santana (UEFS). Email: bejarano@ufba.br 


\section{INTRODUÇÃO}

Muitos cursos de formação de professores passaram a dedicar boa parte da carga horária de disciplinas da área de formação pedagógica para o estudo da teoria histórico-cultural de Vygotsky e de suas implicações na prática docente no Brasil, nos últimos tempos. Os documentos oficiais mais recentes, que pretendem orientar a educação básica, têm buscado nessa teoria as explicações sobre os processos de desenvolvimento e aprendizagem. Assim, formulações como as de mediação, zona de desenvolvimento proximal, conceitos cotidianos e conceitos científicos, próprias e pilares da abordagem histórico-cultural, tornaram-se comuns no discurso de professores, coordenadores pedagógicos, diretores, psicólogos, inclusive como termos que pretendem sinalizar que a escola está engajada em um movimento pela inovação pedagógica (SFORNI; GALUCH, 2006).

Sem dúvida, muitos conceitos peculiares à teoria vygotskyana propiciaram mudanças valiosas na organização do ensino, uma vez que contribuíram para se romper com ideias cristalizadas, como, por exemplo, as de que o aluno, por si, constrói o seu próprio conhecimento, e que o mais importante é a escola ensinar o aluno a aprender a aprender. Outra contribuição dessa teoria é a importância de o ensino tomar como ponto de partida os conhecimentos prévios dos alunos acerca dos conteúdos das diferentes áreas do conhecimento (SFORNI; GALUCH, 2006).

É papel da escola usar como ponto de partida os conhecimentos prévios, com o claro objetivo de transformá-los, envolvendo-os em problematizações cujas resoluções exigem novos conhecimentos, por vezes mais complexos do que os iniciais. Procedimentos de ensino dessa natureza favorecem a articulação entre o conteúdo que faz parte do currículo escolar e o seu uso cotidiano. Possibilitam, ainda, a organização de um planejamento adequado às necessidades cognitivas dos alunos (SFORNI; GALUCH, 2006).

Nesse contexto, o ensino de Ciências tem um relevante papel para ajudar as crianças na reorganização do pensamento sobre os fenômenos naturais. Proporcionar experimentos em relação às situações de aprendizagem em sala de aula deve ampliar o domínio das crianças no sentido das suas interpretações acerca de determinados tipos de ideias, mesmo sabendo que elas tendem a usar as compreensões anteriores na prática do dia a dia. Algumas estratégias podem ser usadas para melhorar o ensino via adaptação às ideias prévias dos estudantes: a escolha dos conceitos para ensinar, a escolha das experiências de ensino e a apresentação dos efeitos das atividades propostas (DRIVER, 1985).

Contudo, precisamos considerar, quanto ao uso das recomendações elencadas acima, que nem sempre todos os alunos de uma classe têm ideias prévias acerca de um objeto de estudo. Isso não significa que tal objeto não deva ser estudado, mas que a intervenção do professor será a de apresentar ideias gerais a partir das quais o processo de investigação sobre o objeto possa se estabelecer. A apresentação de um assunto novo para o aluno também é instigante, e durante as investigações surgem dúvidas, constroem-se representações, buscam-se informações e confrontam-se ideias (BRASIL, 1997). 
Podemos ampliar os da matriz teórica de Vygotsky (1991), a partir dos dados da pesquisa (dissertação de mestrado) desenvolvida em sala de aula com os alunos da COOPEC-BA e participação das professoras dessa escola, que está situada na região Noroeste do estado da Bahia, a $500 \mathrm{~km}$ de Salvador (CASTRO, 2010). Esta escola desenvolve um trabalho voltado para a preparação do indivíduo, no sentido de torná-lo apto para compreensão e enfrentamento dos problemas cotidianos, bem como sua autorrealização. A COOPEC atende, geralmente, crianças filhas de servidor público municipal da sede e povoados, com dificuldades financeiras, na sua maioria, por meio das atividades dos professores e demais funcionários, incluindo participação de voluntários. Trata-se, portanto, de um estudo com alunos das séries iniciais ( $2^{\circ}$ ao $5^{\circ}$ ano), com faixa etária entre 07 e 11 anos de idade, com perspectiva de desenvolver neles formas de pensamento mais próximas dos conteúdos científicos que fazem parte da realidade da sala de aula e que são consagrados pela comunidade científica.

\section{ASPECTOS METODOLÓGICOS}

Tivemos como primeira etapa/objetivo do projeto de pesquisa de Mestrado a identificação dos conhecimentos prévios acerca de conceitos de seres vivos nos alunos das séries iniciais da COOPEC (o que eles sabem). Para concretizar esse objetivo, elaboramos entrevistas estruturadas geral (eeg1) para levantamento dos conhecimentos prévios dos alunos no início do $1^{\circ}$ bimestre. Consideramos os seguintes conteúdos para elaboração do eeg1: organização celular, seres vivos e não vivos, ciclo vital e funções vitais (CASTRO, 2010).

Para atender a esse objetivo, apresentamo-lo à direção da escola, coordenação e professores em horários e datas planejadas. Nesse encontro preliminar, definimos a data e o horário para aplicação do primeiro instrumento de pesquisa (entrevista estruturada geral-eeg1) e planejamento das demais atividades previstas no cronograma de pesquisa. Aplicamos, inicialmente, o eeg1 para 08 alunos da COOPEC para fins de validação desse instrumento de pesquisa. Para isso, foi necessário o preparo do ambiente de pesquisa junto aos alunos em sala de aula através da apresentação dos objetivos e da importância da pesquisa para escola, dentre outras ações (CASTRO, 2010).

Iniciamos o trabalho investigativo no nível de desenvolvimento atual dos alunos (conhecimentos espontâneos) (GASPARIN, 2009). A coleta de dados realizada na COOPEC, para fins de diagnóstico, teve duração de (04 h/aula) sendo 1h/aula por turma (eeg1). Em cada turma foram aplicados questionários (eeg1) para que eles descrevessem suas concepções acerca de alguns conteúdos de Ciências Naturais, acerca de seres vivos (CASTRO, 2010).

Os dados coletados nesta pesquisa foram analisados com base na orientação do método dialético (GASPARIN, 2009). O método dialético de elaboração do conhecimento científico escolar pode ser posto em prática tanto como princípio 
geral de todo processo de ensino e aprendizagem quanto na construção mais específica dos conceitos em si. Em ambos os casos, o ponto de partida do trabalho pedagógico é a Prática Social Inicial do conteúdo. Gasparin (2009) menciona as três fases do método dialético de construção do conhecimento escolar: prática-teoria-prática, partindo do nível de desenvolvimento atual dos alunos, trabalhando na zona de desenvolvimento imediato para chegar a um novo desenvolvimento atual. No caso do levantamento dos conhecimentos prévios em questão, seguimos o primeiro passo que trata da Prática Social Inicial do conteúdo ou do conceito que se expressa pela vivência cotidiana na totalidade empírica.

Em cada série, fizemos a comparação das respostas dos alunos de acordo com cada item do questionário para as diferentes questões que compunham o instrumento (eeg1). Vale ressaltar que consideramos as respostas originais dos estudantes, incluindo erros ortográficos e/ou neologismos nas respostas aos itens desses referidos questionários (CASTRO, 2010). Com o diagnóstico adquirido com aplicação das questões referentes à eeg1, descrevemos a prática inicial dos conteúdos proposta por Gasparin (2009).

A pesquisa exploratória de caráter qualitativo (BOGDAN; BIKLEN, 1994) busca, enfim, analisar as questões (eeg1) acerca da compreensão dos conceitos de seres vivos pelas crianças em relação ao contexto da prática exercida pelos professores(as).

Finalizamos o levantamento de dados acerca dos conceitos de seres vivos com aplicação do questionário (eeg2) para as professoras da COOPEC no final do IV bimestre do ano de 2009 (CASTRO, 2010).

Usamos, também, a entrevista estruturada geral, a partir de questionário (eeg2) sobre o ambiente de sala de aula para fins de elaboração de um perfil de conhecimento geral das turmas durante as fases da pesquisa. Esse perfil foi construído nos encontros bimestrais (finalizado no IV bimestre) com as professoras, nos quais elas relataram sobre suas limitações teóricas na área científica da pesquisa, sobre as dificuldades e potencialidades dos alunos e suas curiosidades com relação aos conteúdos conceituais de seres vivos. O contato direto do pesquisador (CASTRO, 2010) com as turmas, durante o ano de 2009, também foi diferencial para a construção do perfil de conhecimento das turmas.

Os dados obtidos por meio dos instrumentos supracitados foram organizados para o planejamento de um curso para professores das séries iniciais de forma a cumprir o último objetivo deste trabalho de investigação (CASTRO, 2010).

Consideramos, enfim, para o desenvolvimento deste trabalho, os conhecimentos prévios como sendo espontâneos ou escolares, e estes últimos, como científicos, de acordo com Vygotsky (1991). Adotamos, também, os conhecimentos cotidianos (tácitos) como saberes prévios que os alunos adquirem no dia a dia em contato com os adultos ou com os meios de comunicação (televisão, internet, etc.) e os saberes escolares como formais, com base em Duarte (2003). 


\section{O CONTEXTO DA SALA DE AULA}

As professoras das séries iniciais têm formação em magistério de $1^{\mathrm{o}}$ grau ( $2^{\circ}$ ano); licenciatura em Pedagogia ( $3^{\circ}$ ano); licenciatura em Letras ( $4^{\circ}$ ano); licenciatura em Biologia ( $5^{\circ}$ ano). Essas professoras aceitaram fornecer dados qualitativos e participar da pesquisa. Elas se predispuseram a participar das atividades interventivas em sala de aula, no tocante ao estudo de conceitos de seres vivos, bem como no apoio ao desenvolvimento de várias atividades durante a realização da pesquisa, tais como: registros fotográficos, filmagem das aulas práticas e orientação na descrição das observações microscópicas feitas pelos alunos (as) sob a forma de texto e/ou desenho (CASTRO, 2010).

O período de trabalho de campo na COOPEC foi de 2009 a 2010, sendo que, no primeiro ano, desenvolvemos (pesquisadores/autores e professoras) atividades de pesquisa e intervenção (aulas práticas) em sala de aula com 63 estudantes; no segundo ano, ampliamos as aulas práticas, seguindo um planejamento baseado na experiência do ano anterior (CASTRO, 2010).

Finalizamos o ano de 2009 com 60 alunos por conta de três transferências escolares. A quantidade de alunos do $2^{\circ}$ ao $5^{\circ}$ ano (2010), por turma, foi a seguinte: no $2^{\circ}$ ano, 18 ; no $3^{\circ} ; 17$, no $4^{\circ}$ e 23 no $5^{\circ}$ ano, num total de 74 estudantes (CASTRO, 2010).

$\mathrm{Na}$ proposta curricular da COOPEC constam as disciplinas Português, Matemática, Ciências, História, Geografia, Artes, Inglês e temas transversais. Os alunos da $2^{\circ}$ ano têm facilidade de compreensão dos conteúdos das disciplinas Ciências, Português e Matemática. Eles apresentam dificuldade de compreensão dos conteúdos de Geografia e Inglês. Os alunos são curiosos com os assuntos de Ciências. Eles gostam de desenvolver tarefas sobre a germinação de sementes; observar o desenvolvimento das "plantinhas" (ciclo vital); fazem comparação desse fenômeno com o ciclo de vida do ser humano. Os alunos tiveram grande entusiasmo em observar e caracterizar a forma microscópica dos seres vivos (vegetais). Com isso, puderam ampliar a visão que eles apresentaram anteriormente sobre os organismos pequenos (CASTRO, 2010).

Os alunos do $3^{\circ}$ ano têm muito interesse pelos conteúdos apresentados nas aulas de ciências e desenvolvem com afinco as tarefas propostas pelas professoras. Eles têm, em geral, dificuldades de compreensão da disciplina Matemática e facilidade em História e Geografia. Entretanto, Ciências é o componente curricular que desperta mais curiosidade, especialmente no que se refere aos conteúdos de plantas e seres vivos em geral. A professora dessa série relatou que as atividades práticas de ciências aplicadas (experiências em sala), após a exposição de conteúdos, estimularam um maior envolvimento e desempenho dos alunos nas aulas de Ciências. Portanto, segundo a professora, a intervenção poderá ser algo a acrescentar muito no conhecimento deles, aumentando a curiosidade para que eles se tornem críticos, reflexivos e possam construir um conhecimento acerca dos conteúdos a serem estudados (CASTRO, 2010). 
Os alunos do $4^{\circ}$ ano têm facilidade de compreensão dos conteúdos das disciplinas Inglês, Ciências e Língua Portuguesa, e mostram dificuldade em História, Geografia e Matemática. São curiosos acerca dos assuntos de Ciências, como os tipos de solo e animais (vertebrados invertebrados e corpo humano, especialmente nos sistemas circulatório e digestório). Eles gostam de realizar experiências, interpretar atividades ilustrativas, enigmas, cruzadinhas e desenvolver atividades em grupo, no geral ou em dupla; gostam de pesquisar as suas curiosidades e/ou dúvidas sobre fenômenos naturais (CASTRO, 2010).

Os alunos despertam mais interesse para os seres vivos que não podemos observar a olho nu, e começaram a dar importância a alguns detalhes como: cor, cheiro, forma e o aspecto, por exemplo, de uma matéria em decomposição (folha). Eles acrescentam outros exemplos, tais como "machucado no corpo", "ferida", "arranhão", "massa nos dentes sujos", "sabores em relação à higiene bucal, antes e após a escovação", "a flora intestinal", "o funcionamento da digestão do alimento (da deglutição ao bolo fecal)" $e$ "uso do alimento como adubo, inclusive o esterco de animais" (CASTRO, 2010).

Houve muitos questionamentos, após a nossa intervenção, com relação ao formato das células que eles observaram ao microscópio; muitos alunos fizeram comparações com objetos ou animais. Alguns deles questionaram de onde os seres microscópios vinham ou como se reproduziam (CASTRO, 2010).

Castro relata que os alunos do $5^{\circ}$ ano têm facilidade de aprendizagem em Ciências, Matemática e História. Eles apresentam curiosidade para os conteúdos de célula e de seres vivos, bem como de aspectos reprodutivos humanos. A turma gosta e se interessa em desenvolver atividades em grupo, principalmente sobre os conteúdos referentes aos seres vivos. Após a nossa intervenção, eles afirmaram que as aulas de Ciências deveriam ser mais dinâmicas e realizadas com o uso do microscópio e de atividades de campo. Afirmaram, ainda, que o uso dessas referidas práticas de ensino (planejamento) facilita na compreensão dos conteúdos ensinados.

Esta pesquisa com os alunos e com a participação efetiva dos professores ganhará força à medida que os dados se demonstrarem suficientes como alternativas para o professor ampliar sua prática no sentido de planejar e exercitar melhor sua atividade docente (CASTRO, 2010). Assim, como afirma Duarte (2003), o professor reflexivo poderá adotar uma pedagogia não pautada “apenas" no saber escolar (representações formais) e concentrar sua ação nas "representações figurativas" contidas no conhecimento-ação dos alunos (conhecimento cotidiano, tácito). Esses conhecimentos dos alunos foram evidenciados à medida que eles ofereceram à escola suas formas de compreensão acerca dos conceitos de seres vivos trazidos da experiência diária.

Numa educação em que se valorizam os fins e não os meios que levam à construção do conhecimento, uma análise nessa dimensão poderá ser referencial para os professores passarem a ver o seu trabalho como uma experiência profissional de valor e inter-relacionada com a vida cotidiana (CASTRO, 2010). 


\section{OS CONHECIMENTOS PRÉVIOS DOS ALUNOS DA COOPEC SOBRE SERES VIVOS}

No tocante às dificuldades dos professores em sala de aula quanto aos aspectos de seres vivos propostos, eles relataram que precisam valorizar alguns conteúdos sobre os quais as crianças têm mais interesses e são curiosas, mas nem eles, nem os livros didáticos trazem respostas para satisfazer as necessidades desses aprendizes; às vezes, eles buscam esses conhecimentos em outras fontes como enciclopédias, internet, ou recorrem a experimentos na tentativa de elucidar tais questionamentos dos alunos. Entretanto, reconhecem que mesmo conseguindo respostas para as questões levantadas pelos alunos(as), falta argumento para ampliar-lhes a compreensão dos conteúdos. Percebe-se uma lacuna entre o conhecimento escolar (científico) e o conhecimento espontâneo, presente no cotidiano dos estudantes (CASTRO, 2010).

A busca para conhecer o que os alunos não sabem em relação aos conteúdos de seres vivos (identificação, tamanho, grupos, funções, etc.), a partir de seus conhecimentos prévios, pode representar uma alternativa importante para preencher a lacuna citada anteriormente. A análise dos questionários, que continham questões genéricas sobre os seres vivos, mostrou dois (02) elementos importantes em nível de especificidade: a noção de tamanho e, principalmente, as funções de seres vivos. Eles evidenciaram um conhecimento considerável nos conteúdos identificação dos seres vivos, na distinção entre ser bruto e ser vivo, ciclo de vida e nas diferenças entre animais e plantas (CASTRO, 2010).

Nas questões referentes ao tamanho e às funções vitais de seres vivos, como alimentação, crescimento, respiração, configurou-se, de acordo com o Quadro 1, uma possibilidade para estudo das necessidades de aprendizagem das crianças, ou seja, propiciar condições para o ensino, a partir do que eles não sabem para o que eles precisam saber. Percebeu-se duas situações nessa direção: uma em que falta conhecimento prévio por parte dos alunos(as) sobre algumas questões (conceito A/I, QUADRO 1), e outra em que tal conhecimento se apresenta de forma regular (R), ou suficiente (S). Essas questões podem ser usadas para auxiliar na identificação dos grupos de seres vivos (CASTRO, 2010). 
Os conhecimentos prévios dos estudantes da COOPEC

\begin{tabular}{|c|c|c|c|c|c|c|c|c|c|c|c|c|}
\hline QUUESTÕES/ & \multicolumn{3}{|c|}{$2^{\circ} \mathrm{ANO}$} & \multicolumn{3}{|c|}{$3^{\circ} \mathrm{ANO}$} & \multicolumn{3}{|c|}{$4^{\circ} \mathrm{ANO}$} & \multicolumn{3}{|c|}{$5^{\circ} \mathrm{ANO}$} \\
\hline Níveis/respostas & $\mathrm{I} / \mathrm{A}$ & $\mathbf{R}$ & s & I/A & $\mathbf{R}$ & s & I/A & $\mathbf{R}$ & $s$ & I/A & $\mathbf{R}$ & $\mathrm{s}$ \\
\hline $\begin{array}{l}\text { 1- Qual dos } \\
\text { seguintes corpos } \\
\text { são seres vivos? } \\
\text { Pedra, flor, água, } \\
\text { coração, planta... }\end{array}$ & 2 & - & 9 & 1 & 4 & 7 & 5 & 6 & 8 & 1 & 3 & 10 \\
\hline $\begin{array}{l}\text { 2- Como se } \\
\text { diferencia um } \\
\text { ser vivo de um } \\
\text { ser bruto? }\end{array}$ & - & - & 11 & 1 & - & - & 14 & - & 5 & 3 & - & 11 \\
\hline $\begin{array}{l}\text { 3- Existem } \\
\text { seres vivos tão } \\
\text { pequenos que } \\
\text { não podemos } \\
\text { ver? Quais? Fale } \\
\text { um pouco deles. }\end{array}$ & 11 & 4 & 6 & 3 & - & 9 & 6 & - & 13 & 2 & - & 12 \\
\hline $\begin{array}{l}\text { 4- Como é o ciclo } \\
\text { de vida dos seres } \\
\text { vivos? Explique. }\end{array}$ & 2 & - & 9 & 1 & - & 11 & 12 & 7 & 4 & - & 10 & \\
\hline $\begin{array}{l}\text { 5- De que forma } \\
\text { você diferencia } \\
\text { um animal de } \\
\text { uma planta? }\end{array}$ & 4 & - & 7 & 3 & - & 9 & 8 & - & 11 & 3 & - & 11 \\
\hline $\begin{array}{l}\text { 6- Como se } \\
\text { alimentam e } \\
\text { crescem? Um } \\
\text { animal, uma } \\
\text { planta e você? }\end{array}$ & 3 & - & 8 & 3 & - & 9 & 4 & 3 & 12 & 3 & - & 11 \\
\hline $\begin{array}{l}\text { TOTAL DE } \\
\text { ALUNOS-56* }\end{array}$ & \multicolumn{3}{|l|}{11} & \multicolumn{3}{|l|}{12} & \multicolumn{3}{|l|}{19} & \multicolumn{3}{|l|}{14} \\
\hline
\end{tabular}

QUADRO 1: Fonte: COOPEC, Central-BA, 2009- 07 alunos ausentes - total de 63*

LEGENDA: Trata-se de conhecimentos espontâneos e escolares $\mathrm{I} / \mathrm{A}=$ Ausência ou insuficiência das respostas dos alunos $\mathrm{R}=$ Respostas regulares dos alunos $S=$ Respostas suficientes dos alunos - = Ausência de resposta dos alunos

Em linhas gerais, a maioria dos alunos tem conhecimento espontâneo suficiente para os itens perguntados. Observa-se que pelo menos 02 alunos em cada série $\left(2^{\circ}\right.$ ao $5^{\circ}$ ano) não associam os órgãos, ou parte dos seres vivos, como seres vivos/estruturas vivas (questão 01). Aparece, no $2^{\circ}$ e $5^{\circ}$ ano, a diferenciação entre um ser vivo e um ser bruto, a partir de uma "funcionalidade espontânea", ou seja, "um ser bruto é valente"; "um ser vivo é normal", ou ainda associando características anatômicas como, "um servivo tem coração, uma pedra não tem" (CASTRO, 2010). Com base 
em Cunha e Justi (2008), o primeiro se refere ao uso de uma analogia funcional pela criança, enquanto o segundo exemplo se refere ao uso de uma analogia estrutural.

Castro (2010) afirma que há muito conhecimento espontâneo e pouco conhecimento escolar acerca dos conceitos de seres vivos em geral (QUADRO 2). Segundo Pines e West (1984), esse tipo de aprendizagem é classificado como situação espontânea/ não instruida, pois o conhecimento espontâneo é extenso, rico e suficiente, e não há conhecimento escolar correspondente a ser apresentado.

A maioria dos alunos(as) do $2^{\circ}$ ao $5^{\circ}$ ano apresenta conhecimento espontâneo sobre os aspectos identificação/tamanho/função dos seres vivos microscópicos (exceto o $2^{\circ}$ ), quando inquiridos sobre a questão 03 . Isso sugere uma deficiência em nível de correlação de tais aspectos com os conteúdos que se espera ser tratados em sala de aula, como exposto na descrição a seguir (CASTRO, 2010):

0 conhecimento sobre microorganismos- Alunos da COOPEC

\begin{tabular}{|c|c|c|}
\hline ANO & No DE ALUNOS(AS) - IDENTIFICAC̣ÃO & DESCRIC̣ÃO/ FUNC̣ÃO* \\
\hline $2^{\circ}$ & $\begin{array}{l}\text { 4- micróbios } \\
\text { 5- micróbios/bactérias }\end{array}$ & - doenças-febre p.ex. \\
\hline $3^{\circ}$ & $\begin{array}{l}\text { 2- bactérias/vermes } \\
4 \text { - micróbios } \\
\text { 3- mosquitos, formiga, pulga }\end{array}$ & $\begin{array}{l}\text { - pulga é um animal bem } \\
\text { pequeno e vive em } \\
\text { um cachorro }\end{array}$ \\
\hline $4^{0}$ & $\begin{array}{l}\text { 2- micróbios } \\
\text { 11-cobra, mosquito, mosca, rã, minhoca, pulga, aranha }\end{array}$ & $\begin{array}{l}\text { - mosquito, eu não } \\
\text { encontro porque ele é } \\
\text { muito pequeno }\end{array}$ \\
\hline $5^{\circ}$ & $\begin{array}{l}\text { 3- micróbios/verme, pulga, cachorro } \\
\text { 9- micróbios/germes/seres unicelulares }\end{array}$ & $\begin{array}{l}\text { - verme, formiga, } \\
\text { micróbios são muito } \\
\text { pequenos e, os vermes } \\
\text { causam doenças }\end{array}$ \\
\hline
\end{tabular}

QUADRO 2: Fonte: COOPEC, Central-BA, 2009.

*(Os alunos (as) com respostas Insuficientes/Ausentes (I/A) não foram referenciados nessa descrição da questão 03Existem seres vivos tão pequenos que não podemos ver? Quais? Fale um pouco deles.)

Os estudantes do $2^{\circ}$ ano tendem a relacionar os seres pequenos com alguma função, mesmo sem a noção de sua dimensão física. Tal relação não aparece no $3^{\circ}$ e $4^{\circ}$ ano, quando eles atestam a dificuldade de reconhecer a diferença de tamanho entre seres microscópico-macroscópicos, colocando em igualdade micróbio/verme, mosquito e pulga, conforme os exemplos: pulga é um animal bem pequeno e vive em um cachorro... mosquito, eu não encontro porque ele é muito pequeno... verme, formiga, micróbios são muito pequenos e, os vermes causam doenças. Neste último exemplo, há um erro conceitual em usar o verme como micro-orgnismo causador de doenças (CASTRO, 2010).

$\mathrm{O}$ número de acertos do $2^{\circ}$ ano em relação à identificação dos micróbios como micro-organismos (09 alunos), sendo que 05 destes ainda reconhecem a funcionalidade desses seres, está atrelada à forma com que o conhecimento escolar 
é mediado com esses estudantes (CASTRO, 2010). Encontramos, na literatura, até o momento, apenas os estudos de Freitas (1989) para explicar essa questão. Este autor argumenta que, nessa série, os conteúdos escolares são desenvolvidos em sala de aula sem considerar um grande número de critérios. Por isso, de uma maneira geral, as crianças tendem a assimilar os conceitos básicos de seres vivos (identificação e função). Esse tipo de aprendizagem caracteriza uma situação formal-simbólica/zero-espontânea, pois existe pouco conhecimento espontâneo para interagir com o conhecimento formal apresentado na escola (PINES; WEST, 1984).

Byrne e Sharp (2006) informam que as crianças maiores conhecem os aspectos de organização celular (uni e pluricelular), mas não avançam na descrição e funcionalidade de micro-organismos. Com base nesses autores, podemos afirmar que os estudantes do $5^{\circ}$ ano da COOPEC distinguem, na sua maioria, os seres microscópicos dos macroscópicos, possivelmente pelo contato com os conteúdos escolares de Ciências nas séries anteriores associado a um melhor desenvolvimento na cognição, conforme mostra o Quadro 2.

Por outro lado, segundo a professora do $5^{\circ}$ ano, os estudantes dessa série ainda não dominam as diferenças entre organismos microscópicos e macroscópicos pequenos, pois

eles acreditam que todos os seres pequenos são formados por uma única célula (unicelulares), ou seja, eles têm dificuldade em identificar organismos unicelulares e pluricelulares, a partir do número de células.

Esses dados sugerem a necessidade de um trabalho em sala de aula sobre a caracterização/importância ou identificação/tamanho/função dos organismos pequenos, como indica a professora do $5^{\circ}$ ano. Ela afirma que poderá trabalhar figuras para explorar esses conceitos com os meninos(as), bem como relata a necessidade do uso do microscópico para diferenciação entre os seres vivos que podem ser vistos ou não a "olho nu", como ponto de partida para tal estudo (CASTRO, 2010).

Percebemos a necessidade de trabalhos práticos referentes ao ciclo de vida (questão 04), principalmente no $4^{\circ}$ ano, como por exemplo metamorfose de insetos e girinos; germinação de sementes e desenvolvimento de plantas locais, de ciclo de vida curto (feijão). Parte dessa última prática (germinação) é comumente realizada na escola todo ano, no curso primário, como atestam as professoras. Além disso, é comum no ambiente escolar próximo à sala de aula, a presença de larvas de insetos que tecem seus casulos e, na lagoa da cidade, os girinos que se transformam anfíbios adultos, no início das chuvas de verão (CASTRO, 2010).

Os alunos, em geral, usam caracteres externos (folhas, pernas) e/ou internas (pulmão, sangue, seiva) para diferenciar um animal de uma planta (questão 5). O $2^{\circ}$ e o $5^{\circ}$ ano apresentaram indícios de uma diferenciação entre animais e plantas, a partir das funções anatômico/funcionais (analogias), como ilustram o exemplo a seguir (CASTRO, 2010): 
a planta não tem olho e boca e o animal, tem... a planta tem folha e raizes e o cachorro tem pernas... o animal é carnivoro e a planta, não... os animais têm carnes no corpo e as plantas, folhas e galhos... os animais se mexem e a planta, não... a planta nasce da terra e o animal, não... o animal respira oxigênio e, a planta gás carbônico (alunos das séries iniciais da COOPEC).

Segundo Castro (2010), a maioria dos alunos demonstra conhecer como se alimenta os seres vivos (questão 06), inclusive eles mesmos (hábito alimentar), entretanto, não conseguem relacionar a alimentação com crescimento de animais e plantas. Eles emitem uma resposta só (tautológica) para esse fenômeno sem evidenciar qualquer processo que implica na relação dos alimentos para o crescimento dos organismos vivos. De acordo com Vygotsky (1991), essas respostas dos estudantes ocorrem por conta da falta do conhecimento escolar (consciência) correspondente aos conteúdos mencionados no excerto anterior.

Para alunos (as) do $2^{\circ}$ ano, obtivemos como respostas mais comuns: as plantas se alimentam de água, os animais se alimentam de comida, e o ser humano (ele) se alimenta de água e comida; no $5^{\circ}$ ano apareceram descrições em que as plantas se alimentam de água, luz e sais minerais; os animais (incluindo ele) se alimentam de fontes alimentares variadas, incluindo os termos carnívoros, herbívoros e onívoros (CASTRO, 2010).

As crianças, em geral, usaram os conhecimentos imediatos para diferenciar as plantas dos animais. Esse mecanismo ocorre porque, segundo Vygotsky (1991), a criança percebe primeiramente as diferenças entre os objetos e/ou fenômenos para depois perceber as semelhanças (lei das diferenças e semelhanças). No $5^{\circ}$ ano já se evidencia o uso de percepção das semelhanças pelos estudantes ao trazerem conceitos novos (em nível escolar) para as perguntas, em relação às séries anteriores. Para o uso dos termos herbívoros, carnívoros e onívoros é requisitado conhecimento de características similares (estrutura do corpo e tipo de alimento) para as espécies de seres vivos assim classificados (grifos nossos). Esses conhecimentos foram fundamentais para elaboração de um planejamento de ensino de Ciências para as crianças do Ensino Fundamental da COOPEC.

\section{PLANEJAMENTO DE ENSINO DE CIÊNCIAS PARA AS SÉRIES INICIAIS}

A partir da experiência inicial (aplicação de questionários) com pesquisa para a dissertação de Mestrado, foi possível a elaboração de uma proposta de curso/ planejamento que possa contribuir para ampliar a formação continuada dos professores das séries iniciais, na área do ensino de Ciências. Essa proposta considerou, essencialmente, o conhecimento dos alunos no tocante a conceitos de seres vivos e os processos envolvidos na compreensão desses conceitos (CASTRO, 2010).

Consideramos as respostas apresentadas pelos estudantes como recurso motivador para professoras iniciarem suas aulas sobre seres vivos. Esses alunos apresentaram novos ou mais fortes pontos de vistas/dúvidas acerca 
dos conteúdos espontâneos e/ou científicos. Com isso, os docentes puderam planejar e desenvolver melhor as atividades práticas para atender às demandas de conhecimentos dos estudantes.

O planejamento inicial com as professoras foi realizado na semana pedagógica em fevereiro de 2010, culminando com o esboço dos miniprojetos a serem desenvolvidos durante aquele ano letivo, a saber: "Os seres vivos que não podemos ver (invisíveis ao olho nu)"; "Funções vitais da plantas" e "Funções vitais dos animais". O miniprojeto "Os seres vivos invisíveis ao olho nu", foi finalizado após o contato desses docentes com os alunos na $1^{\text {a }}$ semana de aula. As aulas práticas com os micro-organismos foram realizadas no primeiro bimestre. As atividades desenvolvidas envolveram os conteúdos saneamento, higiene, decomposição e doenças durante os 4 (quatro) bimestres letivos para fins de acompanhar a sequências destes desses assuntos no livro didático. Os miniprojetos "Funções vitais da plantas" e "funções vitais dos animais" foram elaborados/desenvolvidos no primeiro e terceiro bimestres, respectivamente. As atividades práticas foram desenvolvidas pelo pesquisador em todas as etapas planejadas.

Utilizamos 1 hora de aula/prática para cada conteúdo nas 04 (quatro) turmas para os 03 (três) miniprojetos. O miniprojeto "Os seres vivos invisíveis ao olho nu” consta de 03 (três) atividades: demonstração de células macroscópicas (algodão, pelos foliares, gema/ ovo, alvéolo/ limão), observação de amostras de água da chuva e identificação de fungos em pães, queijos e roupa. O miniprojeto "As funções vitais das plantas" contém 06 (seis) experiências práticas: o caminho da água, luz e vida, a germinação de sementes, trocas gasosas, transpiração e identificação de substâncias nos alimentos vegetais. O miniprojeto "As funções vitais dos animais" tem 04 (quatro) experimentos práticos: identificação de gorduras, carboidrato, proteínas e a digestão do amido.

As tarefas teórico-práticas supracitadas foram desenvolvidas pelas professoras ao longo dos bimestres letivos: aula na área verde interno-externa da escola, realização de uma amostra com alimentos e/ou órgãos vegetais, uso do torso para identificar órgãos vitais, a construção de um cardápio alimentar e realização de um "lanche educativo".

$\mathrm{Na}$ perspectiva de atender as 04 (quatro séries) do Ensino Fundamental, os miniprojetos propostos foram ajustados pelas professoras da COOPEC para fins de contribuir para uma melhor sintonia do trabalho docente entre as diferentes séries desse nível de ensino.

O conhecimento espontâneo das crianças foi usado de forma associada aos conteúdos e/ou atividades práticas que constam no planejamento escolar. Esse conhecimento gerou novos questionamentos ao ser mencionado pelas professoras para explicação dos assuntos nas suas aulas de Ciências.

Os saberes/questionamentos apresentados pelos alunos da COOPEC requisitaram o planejamento de novas práticas para serem incorporadas no planejamento escolar de 2011: observação microscópica de pequenos seres pluricelulares (formiga, mosquito, pulgão), experiência sobre transporte de água/nutrientes pela 
raiz (flor de copo de leite) e estudo de nutrientes consumidos a partir dos produtos/tabelas calóricas. A inserção dessas novas práticas poderá se justificar pelo aumento do nível de explicação cobrado pelos alunos em relação à diferenciação entre os seres microscópicos e os macroscópicos pequenos e à interação funcional entre os sistemas orgânicos de animais (ser humano) e plantas (CASTRO \& BEJARANO, 2011).

\section{CONSIDERACְÕES FINAIS}

Pelo exposto, notamos um hiato entre os dois "mundos" de conhecimento (cotidiano e escolar), entre os quais discorremos a nossa discussão neste trabalho. Por isso, entendemos a necessidade de incluir, no planejamento escolar, os conhecimentos espontâneos dos estudantes da COOPEC, experimentos e/ou atividades de ensino capazes de aprimorá-los e contribuir para o desenvolvimento conceitual da criança, numa relação mútua entre as influências dos saberes cotidianos e escolares para tal desenvolvimento. Assim, buscaremos uma forma de conduzir o ensino para uma compreensão conceitual, em vez de apenas mobilizá-lo com vistas à memorização ou conhecimento de conceitos que não contribuem para a evolução do saber científico e funcional da criança (CASTRO, 2010).

A identificação do perfil de conhecimento das turmas e dos conhecimentos prévios dos alunos por parte das professoras da COOPEC se apresentou como uma potencial alternativa para o planejamento e desenvolvimento de um ensino na referida escola, com vistas a atender as reais necessidades de aprendizagem dos alunos. Assim, o ensino planejado e posto em prática buscou envolver tanto as dificuldades (falta de conhecimento) como as potencialidades (conhecimentos prévios) de aprendizagem dos alunos.

Para isso, vale ressaltar o importante papel das professoras da referida escola, no sentido de adequar as atividades práticas dos subprojetos dentro do planejamento geral dos conteúdos que fazem parte das demais disciplinas escolares, sem trazer perdas ao ensino escolar, ainda considerando que as turmas apresentam, também, preferências pelos assuntos e diferenças quanto aos conhecimentos prévios. Além disso, é um trabalho voltado para as características de um público em particular, que são alunos das séries iniciais da COOPEC que exige um cuidado especial (aulas das professoras) na sua aplicação/avaliação dos resultados, sem o qual este trabalho não seria viabilizado e, acima de tudo, por conta de um compromisso com a escola (direção, coordenação e professoras) e com a comunidade (pais) no que tange à ampliação das formas de pensamento dos alunos (CASTRO, 2010). 


\section{REFERÊNCIAS}

BYRNE, J. Progression of children's ideas and understanding about microbial activity. In: CONFERENCE OF THE EUROPEAN SCIENCE EDUCATION RESEARCH ASSOCIATION - ESERA, 4th., 2003, Edinburgh, Scotland. Proceedings ..., Edinburgh: ESERA, 2003. Submitted.

BYRNE, J.; SHARP, J. Children's ideas about micro-organisms. School Science Review, [s.l], v. 88, n. 322, september 2006.

BOGDAN, Robert C.; BIKLEN, Sari Knopp. A investigação qualitativa em educaşão: uma introdução à teoria e aos métodos. Portugal: Porto EditoTRra, 1994.

BRASIL. Ministério da Educação e do Desporto. Parâmetros Curriculares Nacionais: Ciências Naturais. Brasília: SEF, 1997.

CUNHA, M. de C. C.; JUSTI, R. da S. Analogias sobre nutrição e digestão elaboradas por crianças do ensino fundamental. 2008. Disponível em: <www.fae.ufmg.br/abrapec/viempec/CR2/p8.pdf>. Acesso em: 23 mar. 2010.

CASTRO, D. R. Estudo de Conceitos de Seres Vivos nas Séries Iniciais. 2010. Dissertação (mestrado) Universidade Federal da Bahia, Salvador, 2010.

CASTRO, D.R.; BEJARANO, N.R.R.. O conhecimento dos estudantes do Ensino Fundamental I sobre microorganismos: depois das aulas práticas com o microscópio 2. In: ENCONTRO NACIONAL DE PESQUISA E ENSINO DE CIÊNCIAS, 7., 2011. Anais ... Campinas: ENPEC, 2011. (PRELO).

DRIVER, R. Children's ideas in science. Milton Keynes, UK: Open University Press, 1985.

DUARTE, N. Conhecimento tácito e conhecimento escolar na formação do professor por que Donald Shon Não compreendeu Lúria. Educação e sociedade, Campinas, v. 24, n. 83, ago. 2003.

FREITAS, M. A distinção entre ser vivo e ser inanimado: uma evolução por estádios ou um problema de concepções alternativas? Revista Portuguesa de Educação, Minho, Portugal, v. 2, n. 1, p.33-51, 1989.

GASPARIN, João Luiz. A construção dos conceitos científicos em sala de aula. [S.l.s.n.n.], [2009?] Disponível em:< http://www.pesquisa.uncnet.br/pdf/palestraConferencistas/A_CONSTRUCAO_DOS_ CONCEITOS_CIENTIFCOS_EM_SALA_DE_AULA.pdf >. Acesso em: 21 mar. 2009.

PINES, L., West, L. Compreensão conceitual e aprendizado da ciência: uma interpretação da pesquisa dentro de um arcabouco teórico de fontes do conhecimento, 1984. Mimeografado.

SFORNI, M. S. F.; GALUCH, M. T. B. Aprendizagem Conceitual nas Séries Iniciais do Ensino Fundamental. Educar em revista, Curitiba, n. 28, jul-dez, 2006.

SOARES, J. L. Dicionário etimológico e circunstanciado de biologia. São Paulo: Scipione, 1993.

VYGOTSKY, L. S. Pensamento e linguagem. 3. ed. São Paulo: Martins Fontes, 1991.

Data do Recebimento: 07/02/2011

Data de Aprovação: 16/11/2011

Data da Versão Final: 19/12/2011 